\title{
Vitamin D Deficiency in Indian Adolescents
}

\begin{abstract}
AV KHADILKaR
Growth and Pediatric Endocrine Research Unit, Hirabai Cowasji Jehangir Medical Research Institute, Jehangir Hospital, 32, Sassoon Road, Pune 411 001, India. anuradhavkhadilkar@gmail.com
\end{abstract}

I $\mathrm{n}$ humans, the main source of vitamin $\mathrm{D}$ comes from photoconversion of 7-dehydrocholesterol in the skin to cholecalciferol (vitamin D3) by solar ultraviolet radiation (UVB: $290-320 \mathrm{~nm}$ ). Vitamin D formed in the skin or the small amount absorbed from the diet is hydroxylated at the 25 position to produce 25 hydroxyvitamin $\mathrm{D}(25 \mathrm{OHD})$, which is considered to be a reliable index of an individual's vitamin D status. Vitamin D is crucial for calcium homeostasis and musculoskeletal health. Adequate vitamin D status during adolescence might help to reduce the risk of osteoporotic fractures in later life. There is also a growing body of evidence linking vitamin $\mathrm{D}$ status with non-skeletal disorders including autoimmune disorders (Crohn's disease, multiple sclerosis, rheumatoid arthritis, and type 1 diabetes), infections, and risk of developing cancers of the breast, colon, prostate and ovaries(1).

It is intriguing as to why vitamin D deficiency is such a common problem among Indians inspite of abundant sunshine. For example, we found vitamin D status of adolescent girls in Pune (latitude $18.34^{\circ} \mathrm{N}$ ) was similar to that of adolescent girls in Manchester, UK (latitude $53.4^{\circ} \mathrm{N}$ ), assessed during an equivalent season(2). This was probably because Pune girls had very low calcium intake and a high fibre diet which may have led to a depletion of body stores of vitamin D. Other reasons may be genetic factors. For example, South Asians have increased 25(OH)D-24-hydroxylase, which degrades $25(\mathrm{OH}) \mathrm{D}$ to inactive metabolites(3). More recently, it has been shown that the increment in serum 25OHD in response to treatment depends on the heritability of vitamin D binding protein(4).
While there is no consensus on definitions of vitamin D deficiency and sufficiency, serum concentrations of $<50 \mathrm{nmol} / \mathrm{L}$ are considered to be the lower acceptable level by Lawson Wilkins Pediatric Endocrine Society in the USA(5). In spite of widespread vitamin D deficiency, it is surprising that the Indian Council of Medical Research, even in its current updated guidelines does not give any specific recommendations for Vitamin D intake, as it is believed that we Indians get sufficient Vitamin D from sunlight.

The study by Marwah and colleagues(6) published in this issue of Indian Pediatrics has shown that adolescents in Delhi from upper and lower socioeconomic groups had mean serum $25 \mathrm{OHD}$ concentration of $31 \mathrm{nmol} / \mathrm{L}$. The authors also found that despite supplementation with 60,000 IU of Vitamin D3 (monthly 2000 IU/day or twomonthly $1000 \mathrm{IU} /$ day, only $47 \%$ subjects were vitamin D sufficient at the end of one year (mean $25 \mathrm{OHD}$ level $50.1 \mathrm{nmol} / \mathrm{L}$ ). These varied responses to supplementation suggest that perhaps the response to supplementation may also be attributed to other factors known to affect vitamin D levels such as season, ethnicity, calcium intake, body mass index, physical activity, pollution and skin color.

Marwah, et al.(6) have also found that postsupplementation, serum parathyroid hormone $(\mathrm{PTH})$ values have increased above the baseline levels particularly in the lower socio economic stratum, inspite of increment in serum 25OHD concentration. This was a surprising finding and is difficult to explain. Possible explanations include very low 
dietary calcium to phosphorous ratio in adolescents from the lower socioeconomic group, high dietary phosphorous may have acted as a potent stimulant to the parathyroid glands, and this rise in PTH was possibly not overcome by the post-supplementation increment in serum 25OHD. We have also shown that low dietary calcium intake can result in raised serum PTH concentrations due to reversible end organ resistance to the actions of $\mathrm{PTH}(7)$.

It is becoming increasingly evident that abundant sunshine does not seem to protect Indians from widespread biochemical vitamin D deficiency. Hopefully, results of this important trial will stimulate further research to determine the genetic and environmental factors which are responsible for low serum 25OHD values in India, and the optimum vitamin $\mathrm{D}$ treatment regimens that are necessary to rectify low body stores of vitamin D among Indian children.

Funding: None.

Competing interests: None.

\section{REFERENCES}

1. Holick MF. Vitamin D deficiency. N Engl J Med 2007; 357: 266-281.

2. Khadilkar A, Das G, Sayyad M, Sanwalka N,
Bhandari D, Khadilkar V, et al. Low calcium intake and hypovitaminosis D in adolescent girls. Arch Dis Child 2007; 92: 1045.

3. Awumey EM, Mitra DA, Hollis BW, Kumar R, Bell NH. Vitamin D metabolism is altered in Asian Indians in the southern United States: a clinical research center study. J Clin Endocrinol Metab 1998; 83: 169-173.

4. Fu L, Yun F, Oczak M, Wong BY, Vieth R, Cole DE. Common genetic variants of the vitamin $\mathrm{D}$ binding protein (DBP) predict differences in response of serum 25-hydroxyvitamin D [25(OH)D] to vitamin D supplementation. Clin Biochem 2009; 42: 1174-1177.

5. Misra M, Pacaud D, Petryk A, Collett-Solberg PF, Kappy. Vitamin D deficiency in children and its management: review of current knowledge and recommendations. Pediatrics 2008; 122: 398-417.

6. Marwaha R, Tandon N, Agarwal N, Puri S, Agarwal R, Singh S, et al. Impact of two regimens of vitamin D supplementation on calcium - vitamin D - PTH axis of schoolgirls of Delhi. Indian Pediatr 2010; 47: 761-769.

7. Khadilkar A, Mughal MZ, Hanumante N, Sayyad M, Sanwalka N, Naik S, et al. Oral calcium supplementation reverses the biochemical pattern of parathyroid hormone resistance in underprivileged Indian toddlers. Arch Dis Child 2009; 94: 932-937. 